\title{
LESÕES ORGANOFUNCIONAIS DO TIPO NÓDULOS, PÓLIPOS E EDEMA DE REINKE
}

\section{Organic and functional lesions: nodules, polyps and reinke's edema}

\author{
Carla Aparecida Cielo (1), Leila Susana Finger (2), Juliana de Caldas Rosa ${ }^{(3)}$, Ana Rita Brancalioni (4)
}

\begin{abstract}
RESUMO
Tema: lesões organofuncionais são formações benignas decorrentes de comportamento vocal alterado e inadequado, sendo as mais comuns: nódulos, pólipos vocais e edema de Reinke. Objetivo: realizar um estudo comparativo dos dados descritos na literatura sobre prega vocal normal e afecções organofuncionais do tipo nódulos, pólipos e edema de Reinke. O estudo foi realizado por meio de um levantamento bibliográfico em periódicos indexados no Science Direct, periódicos Capes, LILACS, SciELO, MedLine e Scopus e livros, no período de 1999 a 2010. Conclusão: a distribuição dos constituintes da matriz extracelular da lâmina própria Iw32da mucosa, fibras elásticas, colágenas, ácido hialurônico e fibronectina, encontra-se alterada nas três afecções. Ocorre modificação das características vibratórias de amplitude, propagação da onda de mucosa e simetria do padrão vibratório devido à presença do aumento de massa nas pregas vocais, ao contrário do que se observa nas pregas vocais sem afecção. O sinal perceptivo-auditivo da qualidade vocal encontrado nas três lesões é a rouquidão, seguida da soprosidade e da aspereza (exceção do edema de Reinke), sinalizando a presença de ruído acústico à emissão, estando presente também, no edema de Reinke, o agravamento considerável da frequência fundamental. Quanto à etiologia observou-se a predominância dos usos incorretos, e quanto à incidência, nódulos e edema de Reinke predominam no sexo feminino e pólipos no sexo masculino.
\end{abstract}

DESCRITORES: Prega vocal; Laringe; Distúrbio da Voz; Disfonia; Voz

\section{INTRODUÇÃO}

Lesões organofuncionais são formações benignas decorrentes de comportamento vocal alterado e inadequado, sendo as mais frequentes os nódulos, os pólipos vocais e o edema de

(1) Fonoaudióloga; Professora Adjunta dos cursos de Graduação em Fonoaudiologia e Pós-Graduação em Distúrbios da Comunicação Humana do Departamento de Fonoaudiologia da Universidade Federal de Santa Maria, UFSM, Santa Maria, RS; Doutora em Linguística Aplicada pela Pontifícia Universidade Católica do Rio Grande do Sul.

(2) Fonoaudióloga da Prefeitura Municipal de Portão; Mestre em Distúrbios da Comunicação Humana pela Universidade Federal de Santa Maria - UFSM, Santa Maria, RS.

(3) Fonoaudióloga da Prefeitura Municipal de Gaspar - Secretaria de Educação - Serviço de Fonoaudiologia, Psicopedagogia e Psicologia Escolar - SEFOPPE.

(4) Fonoaudióloga da Prefeitura Municipal de Caseiros; Mestre em Distúrbios da Comunicação Humana pela Universidade Federal de Santa Maria - UFSM, Santa Maria, RS.

Conflito de interesses: inexistente
Reinke ${ }^{1,2}$ o que motivou o estudo destas três afecções. Essas lesões provocam alterações na estrutura de camadas da prega vocal que interferem no padrão vibratório, ocasionando mudanças nas características vocais ${ }^{3}$.

Lesões como nódulos, pólipos vocais e edema de Reinke desafiam os pesquisadores quanto ao estabelecimento de seu quadro histopatológico ${ }^{1,3-6}$, inclusive alguns autores ${ }^{4}$ sugerem que as suas características histológicas se sobrepõem. Assim, normalmente, tais lesões são classificadas de acordo com o aspecto macroscópico e com os dados clínicos ${ }^{1,3}$. O avanço de pesquisas sobre biologia molecular tem propiciado melhor compreensão da composição do espaço de Reinke e com isso auxiliado a diferenciação das diferentes afecções ${ }^{3}$. Visando a auxiliar os profissionais fonoaudiólogos e otorrinolaringologistas na maior compreensão das características dessas lesões, com consequências positivas sobre seus planos de avaliação e tratamento, foi realizado um levantamento bibliográfico sobre o assunto. 
O objetivo deste trabalho foi realizar um estudo comparativo dos dados descritos na literatura sobre prega vocal normal e afecções organofuncionais do tipo nódulos, pólipos e edema de Reinke.

\section{MÉTODO}

Para esta revisão de literatura, realizou-se uma consulta sistemática das publicações científicas nacionais e internacionais publicadas entre 1999 e 2010, utilizando livros e artigos científicos. A pesquisa de periódicos foi realizada nas seguintes bases de dados: Science Direct, periódicos Capes, LILACS, SciELO, MedLine, PubMed e Scopus. Para a busca foram utilizados os termos: nódulos vocais, vocal fold nodules, pólipos vocais, vocal polyps, edema de Reinke, Reinke's edema; prega vocal, vocal folds, voz, voice e disfonia.

Foram incluídos nesta revisão os estudos considerados relevantes para a contemplação do objetivo em questão, totalizando 37 artigos internacionais, 17 artigos nacionais e 4 livros e excluídos aqueles que apresentavam informações que não se enquadrassem ao objetivo do estudo e às normas de publicação do presente periódico. Os resultados da busca foram organizados, apresentados e discutidos em diferentes itens, priorizando a elucidação do objetivo proposto e a apresentação do assunto aos profissionais que atuam na área da voz.

\section{REVISÃO DA LITERATURA}

\section{Histologia e biomecânica das pregas vocais}

$\mathrm{Na}$ década de 70, em seus estudos sobre histologia da prega vocal, Minoru Hirano mostrou que a estrutura da prega vocal é organizada em camadas e que cada camada tem propriedades mecânicas diferentes ${ }^{2,7,8}$. Estas camadas são o epitélio, a lâmina própria da mucosa e o músculo tiroaritenóideo ${ }^{6,8}$.

O epitélio, que é pavimentoso estratificado, pode ser considerado uma cápsula delgada e rígida que mantém a forma da prega vocal ${ }^{2,7-9}$. Uma importante estrutura, considerada uma área de transição entre o epitélio e a camada superficial da lâmina própria é a zona da membrana basal, responsável pela aderência do mesmo à lâmina própria da mucosa, e composta por diferentes tipos de fibras colágenas e de proteínas ${ }^{2,7,8}$.

A lâmina própria da mucosa é composta, principalmente, por matriz extracelular e vasos sanguíneos dispostos paralelamente à sua borda livre ${ }^{2,8,10}$. A matriz extracelular é sintetizada pelos fibroblastos e é constituída por fibras colágenas, fibras elásticas, ácido hialurônico e fibronectina ${ }^{8}$.

As fibras colágenas são as responsáveis pela absorção da força de estiramento aplicada sobre a prega vocal e são relevantes no aumento global da resistência da prega ${ }^{11,12}$. As fibras elásticas são componentes que cedem facilmente a trações mínimas, retomando sua forma inicial tão logo cessem as forças deformantes ${ }^{13}$, e o seu arranjo é paralelo à borda livre da prega vocal ${ }^{2,8,10}$.

A fibronectina é uma molécula de adesão, também responsável pela regeneração ${ }^{8,14,15}$, e seu aumento contribui para a formação de fibrose no lugar da lesão ${ }^{15}$, relacionando-se diretamente com o aumento da firmeza e viscosidade da prega vocal, implicando na falta de propagação da onda mucosa ${ }^{8,14}$.

O ácido hialurônico atua como regulador das propriedades viscoelásticas das pregas vocais, com a função de regulação do conteúdo de água, permitindo a absorção de choque, e protegendo as bordas das pregas vocais do trauma vibratório ocasionado durante a fonação ${ }^{1,8,16-19}$. A remoção de ácido hialurônico da matriz extracelular das pregas vocais relaciona-se com um significativo decréscimo na elasticidade ou firmeza do tecido, bem como a um significativo aumento na viscosidade do tecido, o que confirma a importância do ácido hialurônico nas propriedades biomecânicas das pregas vocais como um "amortecedor" do impacto da fonação ${ }^{8,16,20}$.

A lâmina própria da mucosa é dividida em três camadas: a camada superficial, a camada intermediária e a camada profunda ${ }^{2,6-8}$. A camada superficial, também conhecida como espaço de Reinke, é um tecido que, de forma homogênea, se localiza na adjacência do epitélio e que possui limites profundos bem nítidos. Entre a camada intermediária e a camada profunda, os limites não se mostram nítidos pelas técnicas histológicas e imunohistoquímicas ${ }^{8}$. Ocorre uma diminuição das fibras elásticas e aumento das de colágeno na medida em que se aproxima o corpo da prega vocal ${ }^{2,8}$.

Por vibrar intensamente durante a fonação, a camada superficial da lâmina própria da mucosa, não possui vasos sanguíneos calibrosos, apenas capilares. Apesar de os relatos da literatura sugerirem que esta camada apresente poucos componentes fibrosos, ou seja, fibras elásticas e colágenas, a concentração das fibras apenas na camada profunda não explica completamente muitas propriedades viscoelásticas da lâmina própria, por ser a região que mais vibra durante a fonação, necessita de um arcabouço fibroso para manter a sua integridade estrutural $7,8,11$. A contribuição das fibras colágenas, na camada superficial, 
à fisiologia vocal não foi definida, exigindo mais estudos biomecânicos. Entretanto, o arranjo em forma de rede das fibras pode funcionar como uma estrutura flexível, estabilizando a lâmina própria durante a vibração ${ }^{8,11}$.

A camada intermediária da lâmina própria da mucosa possui baixa celularidade, é rica em fibras elásticas maduras e formada essencialmente por elastina, o que Ihe propicia grande elasticidade. As fibras correm paralelas à borda livre da prega vocal, o que contribui para a capacidade de retorno à posição inicial com o término da força. A elastina tem baixa afinidade pela água, o que contribui para uma viscosidade mais elevada nesta região ${ }^{2,8}$.

A camada profunda da lâmina própria da mucosa é formada por uma rede de fibras colágenas que estão dispostas paralelas à borda livre, não oferecendo obstáculos à fonação por estarem dispostas no sentido da tração $2,8,10$.

A quinta e última camada da prega vocal é constituída pelo músculo tiroaritenóideo, o músculo vocal, que se assemelha aos demais músculos estriados esqueléticos do corpo humano ${ }^{2,7,8}$.

A partir do que foi exposto, é possível compreender o conceito de corpo-cobertura proposto por Hirano, segundo o qual as cinco camadas histológicas da prega vocal são divididas em duas camadas baseadas não na histologia, como se descreveu anteriormente, mas nas propriedades mecânicas da prega vocal. Durante a fonação, a cobertura da prega vocal se move de forma intensa e harmônica, contra a gravidade, enquanto o corpo mantém o tônus e oferece estabilidade ${ }^{2,7,8,21}$.

\section{Vibração das pregas vocais}

A análise da organização estrutural das pregas vocais mostra que há uma variação gradativa na rigidez de cada camada, sendo mais maleável na superfície e tornando-se cada vez mais rígida em direção ao músculo vocal. A diferença de consistência tecidual entre a mucosa e o corpo da prega vocal é de fundamental importância para a formação da onda mucosa, permitindo a ampla gama de ajustes de frequência e intensidade da voz humana. Além da estrutura, o muco que recobre a mucosa mantendo a superfície úmida também é essencial para a vibração adequada ${ }^{2,7-9}$.

Os ciclos vibratórios se dividem em quatro fases: fase fechada, fase de abertura, fase aberta e fase de fechamento. O ciclo glótico se inicia quando a pressão subglótica é maior que a resistência glótica e dá início ao processo vibratório $2,7,21$.

O ciclo de vibração das pregas vocais se inicia quando elas são aduzidas total ou quase totalmente, porém permanecem soltas, de modo a restringir o fluxo de ar que sai dos pulmões. Ao mesmo tempo, as forças de expiração produzem uma quantidade crescente de pressão de ar abaixo das pregas e, quando ela se torna suficiente, elas são afastadas uma da outra, liberando, assim, um sopro de ar para o trato vocal. Essa liberação de ar resulta em uma diminuição imediata da pressão subglótica que, associada à elasticidade do tecido, permite que elas voltem para a posição aduzida e possam ser afastadas novamente, quando a pressão subglótica aumentar, reiniciando o ciclo glótico 2,7,8.

Os ciclos glóticos sucessivos não são exatamente iguais, podendo ser observadas pequenas perturbações no período (jitter) e na amplitude (shimmer) A mensuração da proporção de tempo, durante o ciclo vibratório, em que as pregas estão abertas e fechadas, em falantes normais, mostra que existe uma proporcionalidade na duração das duas fases $2,7,22,23$.

A liberdade de movimentos da cobertura da prega vocal (epitélio e lâmina própria da mucosa) está intimamente relacionada à quantidade de tecido vibrátil e à livre movimentação em todas as direções por parte da lâmina própria. A estrutura da matriz extracelular e a adequada distribuição das fibras elásticas e dos vasos sanguíneos, paralelos à borda livre, são condições propícias à vibração normal das pregas vocais ${ }^{7-10,13,24}$.

A ondulação da camada superficial da lâmina própria ocorre concomitantemente nos planos horizontal, longitudinal e vertical. Durante a movimentação horizontal a mucosa desloca-se por movimentos mediais e laterais; no deslocamento longitudinal a mucosa movimenta-se por movimentos ântero-posteriores, sendo que a pregas vocais abrem-se de trás para frente e fecham-se de frente para trás; durante a movimentação vertical as pregas vocais abrem-se e fecham-se de baixo para cima $2,7,13,24$.

A vibração das pregas vocais produz uma frequência fundamental (número de ciclos vibratórios glóticos por segundo/velocidade de vibração), conforme o comprimento, a largura e a espessura das mesmas (englobando-se músculo e mucosa), que podem ser modificados pelos ajustes musculares laríngeos normais e também pela presença de patologias nas pregas vocais $2,7,22,23,25$. Em geral, aceita-se que haja uma faixa de normalidade/ aceitabilidade da frequência fundamental habitual (frequência fundamental mais usada pelo falante) para homens (de $80 \mathrm{a} 150 \mathrm{~Hz})^{7,8,25}$, para mulheres (de 150 a $250 \mathrm{~Hz}$ ) ${ }^{2,7,26,27}$ e para crianças (acima de $250 \mathrm{~Hz})^{7,8}$. 


\section{Afecções laríngeas organofuncionais do tipo nódulos, pólipos e edema de Reinke}

Lesões organofuncionais como os nódulos, os pólipos e o edema de Reinke, cuja disfonia resultante é denominada de organofuncional, são consideradas afecções benignas decorrentes principalmente de comportamento vocal alterado e inadequado $1,3,28$, geralmente sendo as de maior freqüência na população $1,7,24,29$, o que motivou o presente estudo. Tais lesões não apresentam alterações histológicas nas camadas intermediária e profunda da lâmina própria da mucosa, nem no corpo da prega vocal, apenas no espaço de Reinke ${ }^{1,3,28}$.

As desordens da lâmina própria da mucosa na produção da voz são observadas clinicamente, e pelo aumento de massa e mudanças na rigidez causam modificações nas características vibratórias da prega vocal ${ }^{7,17,30,31}$, lentificando a velocidade dos ciclos e reduzindo/agravando a frequência fundamental. A extensão ou o alcance vocal também se apresentam alterados na presença de maior massa das pregas vocais, havendo limitação no alcance de notas mais agudas, podendo ocorrer falhas (quebras) nos tons mais altos $2,17,32,33$.

Em tais lesões, também pode haver interferência nas características da mobilidade da cobertura e da onda de mucosa que podem estar reduzidas, em casos de rigidez do tecido (nódulos vocais de longa data) ${ }^{15,24,30}$, ou aumentadas, em caso de flacidez do tecido, que se torna anormalmente flexível, como ocorre nos casos de edema de Reinke ${ }^{33}$.

A massa aumentada e a mudança na consistência dos tecidos da cobertura das pregas vocais geram também distúrbios na periodicidade de vibração (assimetria ou anarquia vibratória), na adução das pregas vocais e nas fases do ciclo vibratório, com consequências sobre as características da voz ${ }^{5,17,24,30}$.

\section{Nódulos vocais}

Os nódulos vocais são lesões pequenas, caracterizadas pelo espessamento da mucosa, normalmente bilaterais, estritamente simétricas na borda livre da prega vocal, na junção do terço anterior e médio $5,24,30,34,35$. O aspecto normalmente é esbranquiçado, opaco e firme ${ }^{1,5}$, e apresentam-se móveis com a onda de mucosa durante a fonação ${ }^{1}$. Podem ser fibrosos ou edematosos, o que modifica as características de rigidez da cobertura da prega vocal. Os edematosos são relativamente macios e flexíveis, cujo processo de formação inicia-se com o desenvolvimento de edema e vasodilatação. Com o trauma continuado, o tecido edemaciado passa por hialinização e fibrose, tornando-se mais rígido, com aspecto espesso e fibrótico ${ }^{1,5,30}$.
Estudos recentes têm demonstrado que a produção da voz quando associada a forças excessivas de colisão pode resultar em edema e pressão intravascular aumentada, ocorrendo um extravasamento de eritrócitos, em virtude do aumento de vibração e uma variação na dinâmica dos fluidos na estrutura da prega vocal ${ }^{35}$. Com a manutenção do trauma, estas mudanças podem progredir para uma proliferação epitelial e aumento da fibronectina, em particular, na zona da membrana basal ${ }^{8,14,15,36}$.

Em um estudo ${ }^{1}$ observou-se uma desorganização da zona da membrana basal na prega vocal com nódulos, com maior deposição de colágeno IV e laminina, considerada uma resposta típica ao fonotrauma. Pode ocorrer aumento da espessura da zona da membrana basal, quando comparada às pregas vocais normais ${ }^{1,35,37}$.

A redução de ácido hialurônico na camada superficial da lâmina própria da mucosa de pregas vocais com presença de nódulos pode contribuir para a diminuição da onda de mucosa durante a fonação ${ }^{18}$, em virtude de um significativo decréscimo na elasticidade ou firmeza do tecido, bem como a um significativo aumento na viscosidade do tecido ${ }^{20}$.

A presença aumentada de fibronectina está associada à reparação por sucessivas lesões, decorrente de fonotrauma, uma vez que é encontrada em todos os processos de regeneração celular $8,14,15$. Seu aumento na prega vocal com nódulos, tem sido correlacionado ao decréscimo da propagação da onda de mucosa pelo aumento da firmeza e viscosidade da prega vocal ${ }^{14}$.

Um estudo ${ }^{31}$ realizado com objetivo de aprofundar os conhecimentos sobre a patogênese dos nódulos por meio de simulações da vibração das pregas realizadas com modelo computadorizado tridimensional concluiu que há 3 condições básicas para a formação dos nódulos: fenda posterior, zona de colisão limitada e vibração suficiente para conseguir esse impacto localizado.

A adução discretamente incompleta na região posterior é a primeira condição que propicia um padrão de vibração em ampulheta ${ }^{31}$. A fenda em ampulheta consiste em duas regiões de coaptação glótica ineficiente, um triângulo na região posterior e um fuso na região anterior, podendo ter origem em uma fenda triangular médio-posterior ou triangular de grau dois, com presença de lesão de mucosa, geralmente nódulos ${ }^{7,30}$, o que promove, em função do edema entre o terço anterior e médio, a abertura na região anterior das pregas vocais ${ }^{2} \mathrm{O}$ desenvolvimento da fenda triangular médio posterior é consequência do abuso ou mau uso vocal devido ao atrito no vértice da fenda que geralmente se localiza próxima do terço médio das pregas vocais. 
A etiologia da fenda glótica triangular médio posterior pode ser relacionada à hipertonicidade da musculatura cricoaritenóidea posterior (CAP), pois, este é o único músculo abdutor da laringe e em situação de hipertonicidade sua atividade predomina em relação aos demais, produzindo, então, uma fenda à fonação ${ }^{2,7}$.

Produzir uma zona de colisão limitada, discretamente ventral em relação à porção média da região vibratória só é possível se houver um pequeno grau de curvatura na posição de repouso das bordas livres das pregas vocais em sua porção ventral (característica da laringe feminina). Se essa curvatura é mínima (laringe masculina) o padrão de vibração tem um fechamento semelhante ao de um zíper, sem nenhum ponto específico de colisão ${ }^{31}$.

A adução dorsal incompleta precisa ser compensada por uma maior amplitude vibração, produzida por um aumento da pressão subglótica por fatores comportamentais ou por redução da ativação das forças de tensão da prega vocal por fadiga ${ }^{31}$.

Há um consenso entre os autores de que a causa principal da formação dos nódulos vocais é o uso vocal incorreto ${ }^{7,15,24,30,36,38}$ que origina um trauma mecânico ou fonotrauma em que a força, durante a fonação, é dirigida medialmente à região onde se concentra a maior parte da energia vibratória ${ }^{31}$, ou seja, na borda da junção dos terços anterior e médio da glote. Esse movimento oposicional brusco, realizado de maneira frequente, inicialmente leva a um edema localizado que, posteriormente, por hialinização e fibrose, torna-se firme $1,31,36$.

Outros fatores têm sido citados na origem dos nódulos vocais, como anomalias anatômicas da laringe (micromembrana em comissura laríngea anterior) ${ }^{29,30}$, refluxo gastroesofágico ${ }^{39}$, distúrbios hormonais, e os fatores psicoemocionais ${ }^{40}$. Dessa forma, pode-se dizer que a origem dos nódulos é multifatorial $7,15,36,41$.

A ocorrência de nódulos vocais é maior em mulheres e crianças do que em homens $1,2,7,30,31,42$. No entanto, quando os nódulos vocais estão presentes em crianças, a proporção é maior nos meninos ${ }^{32,41}$.

A constituição glótica de crianças e mulheres jovens apresenta valores menores da proporção glótica (1) em relação aos dos adultos do sexo masculino (1:3), o que reflete a maior tendência de mulheres e crianças a serem mais susceptíveis a lesões por trauma no terço médio da prega vocal $1,2,7,24,31$.

Outro fator predisponente é o fato de as mulheres e crianças possuírem menor concentração de ácido hialurônico na mucosa das pregas vocais, tornandoas suscetíveis ao aparecimento dos nódulos, uma vez que o efeito de amortecimento do fonotrauma pela presença do ácido hialurônico é menor ${ }^{2,7,8,16}$.

A maior prevalência dessas lesões em meninos provavelmente seja resultado de uma solicitação social de um papel mais agressivo ${ }^{43}$.

A incidência, com relação à idade, é maior por volta dos 25 anos. Sua frequência diminui consideravelmente após os 40 anos ${ }^{30}$. A faixa etária levantada em nossa pesquisa reflete o comportamento vocal utilizado no mundo atual, com a vida profissional iniciando mais cedo e encerrando-se tardiamente, e provocando, não raras vezes, aumento do estresse e situações de uso abusivo da voz ${ }^{7,30}$.

Em um estudo realizado com pacientes com diversas lesões não neoplásicas, na avaliação laringológica daqueles com nódulos foi observado que quanto à coaptação glótica, $82 \%$ dos pacientes apresentavam coaptação incompleta com fenda glótica, sendo mais comum a do tipo dupla (37\%), seguida pela triangular médio-posterior $(28 \%)^{29}$.

$\mathrm{Na}$ ocorrência das fendas observa-se redução simétrica da onda de mucosa, ou da amplitude, ou da função vibratória, dependendo do tamanho e grau do edema associado ${ }^{5,7}$. A redução no fechamento glótico é característica de lesão que não permite o fechamento completo, com predominância na fase aberta, resultando numa alta taxa de fluxo aéreo e presença de soprosidade na voz ${ }^{5,30}$.

No exame videolaringoestroboscópico de pacientes com nódulos de um estudo ${ }^{30}$, foram observadas pregas vocais com vibrações simétricas ou discretamente reduzidas. Na literatura estas vibrações são descritas como quase simétricas e com a onda mucosa presente ${ }^{5}$.

O desenvolvimento de nódulos vocais provoca alteração da produção normal da voz, causando disfonia ${ }^{30,36}$. Esta afecção está relacionada predominantemente a uma qualidade vocal do tipo roucosoprosa ${ }^{30,32}$, com grau de severidade dependente do tamanho do nódulo e podendo variar de leve a moderadamente severo. A qualidade vocal resultante é de intensidade baixa e frequência grave, porém devido a compensações para evitar o escape de ar, pode-se encontrar a mesma com intensidade forte ${ }^{30}$.

A massa extra das pregas vocais resulta em maior aperiodicidade de vibração e maior perturbação de frequência, resultando na percepção auditiva de rouquidão e no aumento das medidas de jitter Dependendo do seu tamanho, conforme mencionado anteriormente, o fechamento glótico pode estar incompleto, permitindo maior escape de ar, resultando na percepção auditiva de soprosidade ${ }^{7,30}$. Quando a rigidez da cobertura das pregas vocais está aumentada pela presença de nódulos vocais fibrosos e ou pela rigidez da musculatura 
devido ao excesso de tensão, é possível ocorrer à percepção auditiva de aspereza vocal ${ }^{2,7}$.

Em um estudo ${ }^{44}$ realizado com mulheres, no qual foram coletadas 15 emissões sustentadas da vogal "é', o valor médio da frequência fundamental daquelas com nódulos variou de 202,87 a $210,74 \mathrm{~Hz}$ da $1^{\text {a }}$ a $15^{\text {a }}$ emissão respectivamente, valores ligeiramente mais graves aos observados no grupo controle (mulheres sem queixas ou alterações vocais e/ou laríngeas), cuja variação foi de 221,06 a $230,48 \mathrm{~Hz}$ e aos valores médios de normalidade propostos na literatura $2,26,27$.

A pesquisa citada acima ${ }^{44}$ obteve ainda outras medidas acústicas das vozes de mulheres com nódulos, cuja variação da $1^{\underline{a}}$ a $15^{\underline{a}}$ emissão e o thresh proposto pelo MDVP foram respectivamente: Jitter 1,083 a 1,454 (thresh < 1,04); Shimmer dB 0,282 a 0,360 (thresh < 0,350); Shimmer 3,096 a 3,889 (thresh < 3,810); PHR (proporção harmônicoruído) em dB 0,126 a 0,144 (thresh < 0,140). A análise vocal acústica, em casos de nódulos vocais, revela maior perturbação de frequência (jitter) e de intensidade (shimmer) e aumento das medidas de ruído (traduzidas perceptivo-auditivamente pela rouquidão, soprosidade e aspereza) 2,7,30,32.

\section{Pólipos vocais}

Pólipos são lesões comuns das pregas vocais ${ }^{45-48}$, geralmente unilaterais, podendo ocorrer bilateralmente $5,47,48$, sésseis ou pedunculadas, sendo móveis à fonação, porém sem sincronia com a onda de mucosa, e localizadas no terço anterior da prega vocal ${ }^{1,34}$. Normalmente, estão presentes na margem livre das pregas vocais ${ }^{48}$.

Geralmente, ocorrem na camada superficial da lâmina própria, com presença de vasos dilatados e tecido fibrótico. Apresentam coloração que varia de translúcida a vermelha ${ }^{5}$. Os pólipos vocais podem variar quanto à localização, volume e forma, o que possibilita descrevê-los em vários aspectos ${ }^{48}$.

O pólipo mais frequente é o fibroso, formado por tecido conjuntivo vascularizado. Já o gelatinoso é constituído por tecido conjuntivo frouxo, com poucos vasos sanguíneos e invadido por uma substância de aspecto gelatinoso, sendo menos frequente. O pólipo de natureza hemorrágica é formado por grande número de vasos sanguíneos. A rigidez da cobertura das pregas vocais aumenta quando pólipo é hemorrágico ou fibroso, já no edematoso a rigidez diminui ${ }^{2,7}$.

Histologicamente, os pólipos vocais apresentam edema de estroma com proliferação de fibroblastos, dilatação capilar, e estroma hialino. O volume de edema varia entre os pólipos, mas está sempre presente ${ }^{34,48}$. A presença de sangue recente, fibrina e trombose, confirma o diagnóstico de pólipo ${ }^{45}$.
Nos pólipos vocais, a zona da membrana basal encontra-se espessada, devido aos repetidos traumas resultantes dos usos vocais incorretos, com padrões relativamente anormais das fibras de colágeno tipo IV e fibronectina nas áreas subjacentes às lesões ${ }^{7,48}$.

Assim como nos nódulos vocais, as forças excessivas de colisão podem resultar em edema e pressão intravascular aumentada, em virtude do aumento de vibração e uma variação na dinâmica dos fluidos na estrutura da prega vocal. Em um estudo ${ }^{49}$ foram observadas reações positivas em $51,35 \%$ dos pólipos vocais, sugerindo que a presença deste fator no mucosa de laríngea poderia ser responsável pelo desenvolvimento de nódulos e pólipos.

O ácido hialurônico contribui para propriedades viscoelásticas normais da camada superficial da lâmina própria ${ }^{8,16,20}$ e sua redução pode contribuir para a rigidez dos pólipos e a redução da onda de mucosa durante a fonação ${ }^{7}$. Além disso, o aumento da fibronectina na camada superficial de pólipos está associado ao aumento da rigidez da lâmina própria, observada na videoestroboscopia ${ }^{18}$.

A organização das fibras elásticas modificase de um padrão propício à vibração normal das pregas vocais, paralelo à borda livre, para um arranjo perpendicular que torna a vibração dificultosa, favorecendo a aperiodicidade $2,10,50$.

O principal fator etiológico do pólipo vocal é o fonotrauma, embora esteja associada a um evento agudo ou esforço vocal intenso ${ }^{2,7,46,48,50,51}$ que pode causar rompimento dos capilares, levando à hemorragia, devido aos movimentos da lesão durante a fonação, à exsudação de fibrina, e à proliferação de capilares ${ }^{52}$, geralmente a história clínica aponta uma disfonia de longo prazo, bem como presença de outros fatores irritativos com tabagismo, álcool, aspiração de substâncias químicas agressivas ou atividades respiratórias intensas (tocar instrumentos de sopro) $2,47,48,53$.

Diversos estudos associam alterações estruturais mínimas da cobertura agregadas ao pólipo a uma elevada ocorrência de RGE, tabagismo e usos vocais incorretos nos sujeitos estudados, parecendo o uso vocal incorreto ser o principal fator etiológico dos pólipos vocais ${ }^{7,46-48,51,53}$.

A faixa etária de maior incidência é de 21 a 60 anos, sendo raramente encontrado em crianças ${ }^{48}$. A frequência de ocorrência é maior no sexo masculino ${ }^{1,7,52}$.

Os fatores que definem o pólipo como característico da idade adulta podem estar relacionados ao desenvolvimento do ligamento vocal e aos aspectos comportamentais do homem, uma vez que o gesto fonatório masculino é caracterizado por compressão 
medial elevada e pela configuração glótica masculina, sem fenda fonatória, que favorece o disparo do pólipo após fonotrauma ${ }^{2,7}$.

Os sinais estroboscópicos em pólipos mostram diferenças de fase entre as duas pregas, especialmente onde a lesão está localizada. $O$ pólipo vocal move-se com um ligeiro atraso em relação à prega vocal na qual se localiza, podendo interferir nos seus movimentos vibratórios, resultando em acentuada assimetria ${ }^{34,53}$. Mesmo nos casos de pólipo bilateral, a assimetria de vibração pode estar presente devido ao tamanho das lesões ser, geralmente, assimétrico ${ }^{2}$. O fechamento glótico pode ser incompleto, irregular, com presença de fenda nas regiões anterior e/ou posterior ao pólipo $2,7,34,53,54$.

A amplitude de vibração e a onda de mucosa encontram-se reduzidas ou ausentes na proximidade do pólipo ${ }^{34,54}$. Com a diminuição da vibração da mucosa, ocorre aumento da pressão subglótica e maior esforço necessário para superar a perda de energia durante vibração da prega vocal ${ }^{54}$. O tamanho e a posição dos pólipos estão diretamente relacionados a disfonia ${ }^{53}$.

O aumento de massa da cobertura das pregas vocais resulta em maior aperiodicidade de vibração, maior perturbação de frequência, e maior rouquidão ${ }^{55}$, com soprosidade variável, uma vez que os pacientes com pólipos tem predominância na fase aberta do ciclo vibratório. A presença de aspereza não é comum e reforça a possibilidade de alteração estrutural mínima associada, sendo o pólipo uma reação contralateral $2,7,53$.

O tamanho do pólipo está relacionado à possibilidade de frequência fundamental bifurcada ou dicrótica com presença de sub-harmônico marcado no traçado espectrográfico ${ }^{2,7}$. Um estudo ${ }^{50}$ que avaliou frequência fundamental (f0) em sujeitos com pólipo, antes e após a cirurgia, mostrou que os valores de f0 baixaram em média $10 \mathrm{~Hz}$ um mês após a cirurgia, porém seis anos após a cirurgia os sujeitos voltaram a apresentar valores médios de f0 semelhantes aos da avaliação pré cirúrgica. Fato associado, pelos autores, à presença de abuso vocal. As medidas de jitter e shimmer, bem como o decréscimo das quebras de voz demonstram a melhora da qualidade vocal depois da remoção cirúrgica do pólipo.

Em indivíduos com pólipos vocais as medidas de jitter e shimmer encontram-se aumentadas, bem como as medidas de ruído ${ }^{2,7,50,53}$. Em um estudo ${ }^{53}$ foram observadas as seguintes medidas acústicas em indivíduos com pólipos: jitter 1.986\%; shimmer 5.647\%, vFO 2.096 HZ, NHR 0.158 dB; VTI 0.065; PPQ 1.191\%, APQ 4.156\%. Já no grupo controle as medidas foram: jitter 0.509\%; shimmer $1.845 \%$; vF0 1.117 Hz; NHR 0.111 dB; VTI 0.044; PPQ 0.319\%;
APQ $1.102 \%$, sendo observados valores mais elevados nos pólipos, com significância estatística em todas as medidas, se comparados aos valores do grupo controle.

\section{Edema de Reinke}

O edema de Reinke é uma lesão de característica edematosa e difusa, devido ao acúmulo de fluido que ocupa toda a mucosa da prega vocal, causando deformação na face superior e na borda livre da prega vocal $1,2,7,56$. Pode ser uni ou bilateral, simétrica ou assimétrica sendo séssil e muito móvel durante a fonação ${ }^{1}$.

O edema se desenvolve, geralmente, devido à irritação crônica das pregas vocais que altera a permeabilidade dos vasos capilares, levando ao aumento de fluido tecidual dentro do espaço de Reinke ${ }^{1,56}$. Esse aumento de permeabilidade na formação do edema é também ocasionado por lesão mecânica. A associação da presença de edema nas pregas vocais e do atrito constante durante a fonação é responsável pela manutenção do quadro, num ciclo vicioso ${ }^{1,2,7}$.

Histologicamente, o edema afeta a camada superficial da lâmina própria, com aumento da massa de cobertura e redução de sua rigidez ${ }^{2}$. O arranjo das fibras elásticas modifica-se de um padrão propício à vibração normal das pregas vocais, paralelo à borda livre, para um arranjo perpendicular que torna a vibração dificultosa, favorecendo a aperiodicidade ${ }^{1,10}$.

Em um estudo ${ }^{57}$, verificou-se que o edema de Reinke afeta o espaço subepitelial, com perda das junções intercelulares e aumento dos espaços intercelulares, especialmente nas camadas basal e superficial, observadas à microscopia eletrônica.

O tabagismo parece propiciar a diminuição de velocidade de fluxo sanguíneo pelos capilares, o que aumenta a possibilidade de trombose. Elementos dispersos de sangue e acúmulo de eritrócitos na parede interna dos vasos pode levar à sua oclusão, tornando-os frágeis. O Edema pode retardar o processo normal de angiogênese, resultando em suporte anormal de sangue a tecidos $e$ diminuição da regeneração e remodelamento, os quais são problemas comuns às pessoas expostas ao tabagismo ${ }^{56}$.

Ocorre um aumento de fibronectina na prega vocal com edema de Reinke, com acréscimo da movimentação da onda de mucosa, contrário ao encontrado em nódulos e pólipos vocais, sugerindo a existência de isoformas de fibronectina ${ }^{14,56}$.

Os fatores etiológicos do edema de Reinke, comumente relatados na literatura, estão associados ao tabagismo e ao fonotrauma 2,33,37,56. 
Entretanto, parecem contribuir também para a sua formação, fatores hormonais e infecciosos ${ }^{7}$.

A maior incidência do edema de Reinke é no sexo feminino ${ }^{7,33,37}$. Talvez essa diferença se deva ao fato de que as mulheres procuram mais frequentemente por auxílio especializado, por normalmente apresentarem vozes virilizadas ${ }^{2,7}$.

Pelo fato da instalação desta lesão ser lenta e progressiva, a idade de diagnóstico raramente acontece antes dos 45 anos ${ }^{2,7}$, e sua frequência máxima é em torno dos 50 anos ${ }^{2,58}$.

O fechamento glótico encontrado no edema de Reinke é mais acentuado, porque as pregas vocais são preenchidas com fluído e encontram-se de forma mais firme na linha média da glote, podendo ocorrer um predomínio da fase fechada ${ }^{2}$ ou ainda ser observado fechamento glótico incompleto, com fenda irregular dupla, em lesões assimétricas ${ }^{29}$.

As características vocais encontradas são a rouquidão, a queda na frequência fundamental e o agravamento do pitch, apresentando, às vezes, algum grau de aspereza e soprosidade ${ }^{7}$. A presença de rouquidão deve-se à perturbação da amplitude e à presença de ruído ${ }^{2}$.

A frequência fundamental da fonação é mais baixa do que a esperada para o sexo e a idade do paciente devido ao aumento da massa da cobertura da prega vocal e da consequente redução de sua rigidez, permitindo maiores amplitudes de vibração ${ }^{2}$. Além disso, o edema de Reinke interfere no mecanismo tensor primário da laringe (tireoaritenóideo), e tensor secundário (cricotireóideo), e que afeta a habilidade tensional da laringe ${ }^{7}$.

Em um estudo realizado com mulheres, no qual foram coletadas 15 emissões sustentadas da vogal "é', o valor médio da frequência fundamental daquelas com edema de Reinke variou de 159,59 a $172,77 \mathrm{~Hz}$ da 1aㅡ a 15a emissão respectivamente, valores inferiores aos observados no grupo controle (mulheres sem queixas ou alterações vocais e/ou laríngeas), cuja variação foi de 221,06 a $230,48 \mathrm{~Hz}{ }^{44}$, e aos valores médios de normalidade propostos na literatura ${ }^{2,23,26}$.

A pesquisa citada acima ${ }^{44}$ obteve ainda outras medidas acústicas das vozes de mulheres com edema de Reinke, cuja variação da $1^{\text {a }}$ a $15^{\underline{a}}$ emissão e o thresh proposto pelo MDVP foram respectivamente: Jitter 1,401 a 1,678 (thresh < 1,04); Shimmer dB 0,386 a 0,480 (thresh < 0,350); Shimmer 4,393 a 5,521 (thresh < 3,810); PHR (proporção harmônico-ruído) em dB 0,130 a 0,158 (thresh < 0,140). Estas medidas indicam perturbações de frequência (jitter) e intensidade (shimmer), destacando-se a elevação dos valores de shimmer em função da lentificação da vibração das pregas vocais e do ruído no espectro, devido à rouquidão ${ }^{2}$.
Já PHR pode apresentar valores próximos à normalidade, embora a energia de ruído glótico esteja aumentada ${ }^{2}$.

A Figura 1 apresenta, resumidamente, os achados encontrados na literatura, de acordo com as características estruturais, histológicas vibratórias das pregas vocais, bem como, as características vocais na presença das lesões organofuncionais do tipo nódulos, pólipos e edema de Reinke.

A diferenciação histológica entre nódulos vocais, pólipos vocais e edema de Reinke é muitas vezes difícil, não havendo um quadro histopatológico definido. Assim, normalmente, tais lesões são classificadas de acordo com o aspecto macroscópico e com os dados clínicos ${ }^{1,3-6}$.

Em um estudo ${ }^{1}$ não houve associação significativa entre as variáveis morfológicas do epitélio e as lesões laríngeas avaliadas, não se podendo diferenciar entre nódulos vocais, pólipos vocais e edema de Reinke, baseando-se nas alterações morfológicas do epitélio.

Ainda, com relação à espessura da zona da membrana basal, nos nódulos vocais, a mesma encontrou-se mais espessada em relação aos pólipos e às pregas vocais normais, quando foi utilizada a coloração PAS (ácido periódico de Schiff). Além disso, foi encontrada maior imunoexpressão (deposição) de colágeno IV e laminina na zona da membrana basal dos nódulos vocais ${ }^{1}$, quando comparada aos pólipos e às pregas vocais normais, o que mostra maior desorganização da zona da membrana basal nessa lesão, considerada uma resposta típica ao fonotrauma ${ }^{31,36}$. Quanto ao edema de Reinke, ele não se diferenciou das outras lesões, nem das pregas vocais normais, em relação às alterações da zona da membrana basal ${ }^{1}$.

$\mathrm{Na}$ caracterização histológica, com relação ao diagnóstico das três lesões, a associação de presença de sangue recente, deposições de fibrina e trombose, confirma o diagnóstico de pólipo vocal ${ }^{10,45}$. A presença de espessamento da zona da membrana basal do epitélio, conjuntamente com a ausência de hemorragia e de regiões edematosas, confirma o diagnóstico de nódulo ${ }^{31,36}$. O espessamento da zona da membrana basal do epitélio, associado a regiões edematosas e aumento da espessura das paredes dos vasos submucosos, confirma o diagnóstico de edema de Reinke ${ }^{10,56}$.

Neste sentido, um achado marcante e constante nos nódulos vocais é o depósito de material heterogêneo subepitelial, raramente observado nas demais lesões. Outros achados ultraestruturais de destaque, porém sem determinar especificidade entre as lesões, são áreas as focais de destacamento e de interrupções da membrana basal e o alargamento das junções celulares, levando a 


\begin{tabular}{|c|c|c|c|c|}
\hline & Prega vocal Normal & Nódulos vocais & Pólipos vocais & Edema de Reinke \\
\hline \multicolumn{5}{|c|}{ Características histológicas da prega vocal } \\
\hline Massa/Volume da Mucosa & Sem alteração & $\begin{array}{l}\text { Massa aumentada no local } \\
\text { da lesão }\end{array}$ & $\begin{array}{l}\text { Massa aumentada no local } \\
\text { da lesão }\end{array}$ & $\begin{array}{l}\text { Massa aumentada difusa } \\
\text { em toda a prega vocal }\end{array}$ \\
\hline Rigidez da Mucosa & Sem alteração & $\begin{array}{l}\text { Presente em nódulos mais } \\
\text { antigos }\end{array}$ & Presente & Reduzida \\
\hline $\begin{array}{l}\text { Orientação das fibras } \\
\text { elásticas na mucosa }\end{array}$ & $\begin{array}{l}\text { Paralelas à borda livre da } \\
\text { prega vocal }\end{array}$ & $\begin{array}{l}\text { Perpendicular à borda livre } \\
\text { da prega vocal }\end{array}$ & $\begin{array}{l}\text { Perpendicular à borda livre } \\
\text { da prega vocal }\end{array}$ & $\begin{array}{l}\text { Perpendicular à borda livre } \\
\text { da prega vocal }\end{array}$ \\
\hline $\begin{array}{l}\text { Ácido hialurônico na } \\
\text { mucosa }\end{array}$ & Sem alteração & Reduzido & Reduzido & Normal \\
\hline Fibronectina na mucosa & Sem alteração & Aumentada & Aumentada & Aumentada \\
\hline Epitélio de revestimento & Sem alteração & $\begin{array}{l}\text { queratose, } \\
\text { disqueratose, } \\
\text { hiperqueratose }\end{array}$ & queratose & Normal \\
\hline Zona da Membrana basal & Sem alteração & $\begin{array}{l}\text { Espessada (padrões } \\
\text { anormais de colágeno tipo } \\
\text { IV e fibronectina) }\end{array}$ & $\begin{array}{l}\text { Espessada (padrões } \\
\text { anormais de colágeno tipo } \\
\text { IV e fibronectina) }\end{array}$ & $\begin{array}{l}\text { Perda das junções } \\
\text { intercelulares e aumento } \\
\text { dos espaços intercelulares } \\
\text { regiões edematosas e } \\
\text { aumento da espessura } \\
\text { das paredes dos vasos } \\
\text { submucosos }\end{array}$ \\
\hline $\begin{array}{l}\text { Camada superficial da } \\
\text { lâmina própria da mucosa } \\
\text { (espaço de Reinke) }\end{array}$ & Sem alteração & $\begin{array}{l}\text { acúmulo de líquido e falta } \\
\text { de drenagem linfática } \\
\text { neste } \\
\text { espaço facilita o seu } \\
\text { acúmulo nesta região, } \\
\text { evoluindo com } \\
\text { hialinização, proliferação } \\
\text { de } \\
\text { fibroblastos organização e } \\
\text { fibrose do tecido } \\
\text { conjuntivo }\end{array}$ & $\begin{array}{l}\text { lesão vascular e } \\
\text { extravasamento de } \\
\text { líquidos }\end{array}$ & $\begin{array}{l}\text { aumento da massa de } \\
\text { cobertura e redução de } \\
\text { sua rigidez }\end{array}$ \\
\hline $\begin{array}{l}\text { Camadas intermediária e } \\
\text { profunda da lâmina própria } \\
\text { da mucosa (ligamento } \\
\text { vocal ou transição) }\end{array}$ & Sem alteração & Sem alteração & Sem alteração & Sem alteração \\
\hline $\begin{array}{l}\text { Corpo (músculo } \\
\text { tiroaritenóideo) }\end{array}$ & Sem alteração & Sem alteração & Sem alteração & Sem alteração \\
\hline \multicolumn{5}{|c|}{ Características vibratórias } \\
\hline Periodicidade & Periódica & Aperiódica & Aperiódica & Aperiódica \\
\hline $\begin{array}{l}\text { Configuração glótica à } \\
\text { fonação }\end{array}$ & $\begin{array}{l}\text { Fechamento completo ou } \\
\text { com fenda triangular } \\
\text { posterior ou triangular de } \\
\text { grau } 1\end{array}$ & $\begin{array}{l}\text { Fenda triangular médio- } \\
\text { posterior ou triangular de } \\
\text { grau } 2 \text { ou, em estágio de } \\
\text { grande lesão, Fenda em } \\
\text { ampulheta }\end{array}$ & $\begin{array}{l}\text { Irregular, dependendo do } \\
\text { tamanho e da localização, } \\
\text { pode aparecer em } \\
\text { ampulheta }\end{array}$ & $\begin{array}{l}\text { Fechamento completo ou } \\
\text { irregular dependendo da } \\
\text { simetria ou assimetria da } \\
\text { lesão }\end{array}$ \\
\hline Amplitude & $\begin{array}{l}\text { Dentro dos limites de } \\
\text { normalidade }\end{array}$ & Reduzida no local da lesão & Reduzida no local da lesão & Reduzida \\
\hline Onda de mucosa & $\begin{array}{l}\text { Dentro dos limites de } \\
\text { normalidade }\end{array}$ & Reduzida no local da lesão & $\begin{array}{l}\text { Reduzida ou ausente no } \\
\text { local da lesão }\end{array}$ & Aumentada \\
\hline Simetria das pregas vocais & Simétricas & Regular & Assimétricas & Anormalidades \\
\hline $\begin{array}{l}\text { Irregularidade de borda } \\
\text { livre }\end{array}$ & Ausente & Leve & Extrema & Leve a moderada \\
\hline \multicolumn{5}{|c|}{ Características vocais } \\
\hline $\begin{array}{l}\text { Aspectos perceptivo- } \\
\text { auditivos da qualidade } \\
\text { vocal }\end{array}$ & Adequada, sem ruído & $\begin{array}{l}\text { Rouca e soprosa, podendo } \\
\text { apresentar aspereza }\end{array}$ & $\begin{array}{l}\text { Rouca, soprosa, podendo } \\
\text { apresentar aspereza }\end{array}$ & $\begin{array}{l}\text { Rouca, podendo } \\
\text { apresentar soprosidade }\end{array}$ \\
\hline $\begin{array}{l}\text { Frequência fundamental } \\
\text { habitual }\end{array}$ & $\begin{array}{l}\text { Adequada aos limites } \\
\text { esperados para os sexos }\end{array}$ & De adequada a grave & De adequada a grave & $\begin{array}{l}\text { Grave, podendo se } \\
\text { encontrar virilizada }\end{array}$ \\
\hline $\begin{array}{l}\text { Aspectos acústicos da } \\
\text { qualidade vocal }\end{array}$ & $\begin{array}{l}\text { Dentro dos limites de } \\
\text { normalidade }\end{array}$ & Aumento de ruído & Aumento de ruído & Aumento de ruído \\
\hline Grau de disfonia & Nenhum & Leve & Moderada & Moderada \\
\hline
\end{tabular}

Figura 1 - Características estruturais, histológicas, vibratórias e vocais das lesões organofuncionais, do tipo nódulos, pólipos e edema de Reinke 
alterações estruturais dos desmossomos. Todos esses achados são interpretados pelos autores como resposta do epitélio ao fonotraumatismo, sendo mais evidentes nas lesões relacionadas à elevada demanda vocal, como ocorre nos nódulos vocais ${ }^{37}$.

Em um estudo ${ }^{34}$, por meio da avaliação histológica, não foi encontrada distinção definitiva entre nódulos e pólipos vocais comparando-se a presença de edema, fibrina, e inflamação. A quantidade de edema nessas lesões foi variável, mas estava sempre presente.

Em outra pesquisa ${ }^{10}$, a distribuição de alguns constituintes da lâmina própria da mucosa das pregas vocais (fibras elásticas, colágenas e ácido hialurônico) estava alterada nos nódulos vocais, pólipos vocais e edema de Reinke, principalmente a organização das fibras elásticas. Foram encontrados dois padrões, quanto ao arranjo das fibras elásticas: fibras em arranjo paralelo e em arranjo perpendicular na zona da membrana basal.

$O$ arranjo perpendicular esteve presente nas três lesões, predominantemente nos nódulos, e foi provavelmente induzido por forças mecânicas decorrentes do fonotrauma. A quantidade de fibras elásticas no estroma dos pólipos foi menor do que no edema de Reinke e nos nódulos. A distribuição de fibras colágenas mostrou pouca diferença, e a quantidade de ácido hialurônico no tecido conjuntivo foi igual nas três lesões ${ }^{10}$.

Com relação à fibronectina, a mesma encontrou-se aumentada nos nódulos, nos pólipos vocais e no edema de Reinke. Os autores sugerem que devem existir isoformas de fibronectina, exercendo diferentes funções na determinação da redução ou aumento da mobilidade da onda de mucosa, dependendo da patologia ${ }^{14}$.

Diversos fatores etiológicos estão envolvidos no desenvolvimento das lesões benignas da laringe, como pólipos, nódulos e edema de Reinke ${ }^{33}$, sendo possível identificar o predomínio dos usos incorretos ${ }^{15,24,36,38,46-48,51,53}$. Destacando-se o tabagismo no desenvolvimento do edema de Reinke ${ }^{33,37}$ e o fonotrauma nos nódulos vocais e pólipos vocais $15,24,36,38,46-48,51,53$.

Quanto à configuração glótica, a mais frequente nos casos de nódulos vocais é a fenda triangular posterior ${ }^{30,31}$, nos casos de pólipos vocais o fechamento glótico pode ser incompleto, com presença de fenda irregular ${ }^{29}$, com presença de fenda nas regiões anterior e/ou posterior ao pólipo, e nos casos de edema de Reinke pode ocorrer fenda irregular ${ }^{29}$ ou o fechamento pode ser completo ${ }^{2}$, conforme simetria do edema.

No que diz respeito às fases do ciclo vibratório das pregas vocais, os casos de nódulos e de pólipos vocais apresentaram predominância da fase aberta, embora em menor proporção nos nódulos. Os casos de edema de Reinke mostraram um padrão de fase de fechada ou variável. Quanto à irregularidade da borda da prega vocal, os pacientes com nódulos vocais tendem a exibir apenas leve irregularidade, pacientes com edema de Reinke irregularidade leve a moderada ${ }^{2,7}$. Aqueles indivíduos com pólipos parecem exibir valores mais extremos de irregularidade do que aqueles com nódulos vocais e edema de Reinke $2,7,44,50,53$.

A aperiodicidade, assimetria, irregularidade ou anarquia vibratória estão associadas a mais comum manifestação perceptivo-auditiva de alteração vocal: a rouquidão, geralmente presente nas lesões organofuncionais, como nódulos, pólipos e edema de Reinke ${ }^{30,55}$. Ela manifesta-se por frequência e intensidade reduzidas, com aumento de ruído, sendo considerada, do ponto de vista acústico como um tipo de ruído à fonação ${ }^{2,7,23,55}$.

A massa extra das pregas vocais resulta em maior aperiodicidade de vibração e maior perturbação de frequência, resultando na percepção auditiva de rouquidão e no aumento das medidas de jitter. Dependendo do tamanho dos nódulos e pólipos, conforme mencionado anteriormente, o fechamento glótico pode estar incompleto, permitindo maior escape de ar, resultando na percepção auditiva de soprosidade ${ }^{2,30}$. Os edemas discretos e moderados no edema de Reinke por sua vez, propiciam aumento da fase fechada de fechamento glótico e voz fluida ${ }^{2,7,56}$.

O fechamento ineficiente das pregas vocais resulta em escape de ar durante a fonação, o que confere uma característica vocal perceptivo-auditiva de soprosidade à voz, que leva à sensação de frequência fundamental agravada (pitch grave) e sensação de fraca intensidade (loudness diminuída) 2,7,23. Na avaliação acústica, a soprosidade também mostra-se como um tipo de ruído vocal $2,7,23,58$.

Quando a lesão mostra características teciduais de rigidez, observa-se a presença perceptivo-auditiva de aspereza vocal que também gera uma irregularidade vibratória, percebida, na análise acústica, pela frequência fundamental mais aguda e pelo elevado nível de ruído. Assim, acusticamente, a aspereza assim como a soprosidade e a rouquidão também consiste num tipo de ruído que ocorre no momento da fonação ${ }^{2,7,23}$.

Quando a rigidez da cobertura das pregas vocais está aumentada pela presença de nódulos vocais fibrosos e ou pela rigidez da musculatura devido ao excesso de tensão, é possível ocorrer à percepção auditiva de aspereza vocal. Nos pólipos, por sua vez a presença de aspereza não é comum e sua presença reforça a possibilidade de alteração 
estrutural mínima associada, sendo o pólipo uma reação contralateral ${ }^{2,7,53}$. No edema de Reinke a aspereza não é qualidade vocal frequente ${ }^{2,7}$, uma vez que há uma redução de sua rigidez da cobertura das pregas vocais ${ }^{29,56}$.

Quanto à frequência fundamental, nos nódulos os valores são ligeiramente mais graves que os observados em vozes normais. No caso dos pólipos, seu tamanho pode estar relacionado à possibilidade de frequência fundamental bifurcada ou dicrótica com presença de sub-harmônico marcado no traçado espectrográfico ${ }^{2,7}$. Já no edema de Reinke, a frequência fundamental é mais baixa (a menor dentre as três lesões) do que a esperada para o sexo e a idade do paciente ${ }^{44}$, devido ao aumento da massa da cobertura da prega vocal e da consequente redução de sua rigidez, permitindo maiores amplitudes de vibração, gerando uma voz virilizada em mulheres ${ }^{2,53,56}$.

\section{CONCLUSÕES}

A distribuição dos constituintes da matriz extracelular da lâmina própria da mucosa, fibras elásticas, colágenas, ácido hialurônico e fibronectina, encontra-se alterada nas três afecções estudadas (nódulos, pólipos vocais e edema de Reinke). A organização das fibras elásticas modifica-se de um padrão propício à vibração normal das pregas vocais, paralelo à borda livre, para um arranjo perpendicular que torna a vibração dificultosa, favorecendo a aperiodicidade. A quantidade de ácido hialurônico encontra-se reduzida nos nódulos e pólipos vocais, e a de fibronectina aumentada nas três lesões, afetando as propriedades biomecânicas da lâmina própria da mucosa e interferindo negativamente nas características vibratórias das pregas vocais.

Quanto à etiologia observou-se a predominância dos usos incorretos, e no que tange à incidência observou-se que as alterações do tipo nódulo e edema de Reinke predominam no sexo feminino e as do tipo pólipo no sexo masculino.
As lesões organofuncionais aqui discutidas, nódulos, pólipos vocais e edema de Reinke, localizam-se na camada superficial da lâmina própria da mucosa das pregas vocais, que é a responsável pela vibração normal das pregas vocais. Portanto, as características vibratórias da prega vocal, com a presença destas patologias, estarão alteradas. Observou-se que ocorre modificação do padrão vibratório, devido à presença do aumento de massa nas pregas vocais, em função da lesão, com aperiodicidade de vibração, ao contrário do que se observa nas pregas vocais sem patologia. As características vibratórias de amplitude, propagação da onda de mucosa e simetria estão alteradas, quando comparadas ao padrão de normalidade.

O sinal e sintoma perceptivo-auditivo da qualidade vocal encontrado nas três lesões estudadas é a rouquidão (decorrente da aperiodicidade vibratória), seguida da soprosidade (decorrente do escape de ar transglótico não sonorizado durante a fonação) e da aspereza (decorrente do atrito do ar transglótico sobre superfície mais rígida à fonação, com exceção do edema de Reinke), todos os três sinalizando a presença de ruído acústico à emissão. Está presente também, no edema de Reinke, o agravamento considerável da frequência fundamental, podendo tornar a voz virilizada nas mulheres.

Quanto ao grau de fechamento glótico, nas três lesões pode ocorrer um fechamento incompleto, gerando a percepção de soprosidade na voz, salientando-se que, no edema de Reinke, pode ocorrer fechamento glótico completo, como ocorre com pregas vocais normais, dependendo da simetria da lesão.

Desta forma, a avaliação otorrinolaringológica clínica pode utilizar-se de dados descritivos sobre as características macroscópicas das lesões e de seus respectivos padrões de fechamento glótico, e a avaliação fonoaudiológica pode auxiliar a identificar as características de massa e de rigidez das lesões por meio da análise perceptivo-auditiva e acústica da voz. 


\section{ABSTRACT}

Background: vocal nodules, vocal polyps and Reinke's edema are the most common benign organic lesions resulting from vocal misuse or abuse. Purpose: to conduct a comparative study about the normal vocal folds and the benign organic lesions, nodules, polyps and Reinke's edema. The study was performed using a literature review in indexed journals at Science Direct, Capes, LILACS, SciELO, MedLine and Scopus and books from 1999 to 2010. Conclusion: the distribution of extracellular matrix components of the proper lamina of the mucosa, elastic fibers, collagen fibers, hyaluronic acid and fibronectin is altered in all three disorders. There is a change in vibratory characteristics concerning amplitude, mucosal wave velocity and symmetry of vibratory pattern due to presence of increased mass in the vocal cords, contrary to what is seen in vocal cords with no disorder. Perceptual-auditory signal of vocal quality found is hoarseness, followed by breathiness and roughness (except for Reinke's edema), during speech production. In Reinke's edema, considerable reduction of voice fundamental frequency was also present. In all three lesions, there might be an incomplete glottal closure, but in Reinke's edema, depending on lesion symmetry, there may be complete glottic closure. As far as etiology is concerned, incorrect uses prevailed; as to incidence, nodules and Reinke's edema were predominant in females, and polyps were more frequent in males.

KEYWORDS: Vocal Cords; Larynx; Voice Disorders; Dysphonia; Voice

\section{REFERÊNCIAS}

1. Neves BM, Neto JG, Pontes P. Diferenciação histopatológica e himunoistoquímica das alterações epiteliais no nódulo vocal em relação aos pólipos e ao edema de laringe. Rev Bras Otorrinolaringol. 2004; 70(4): 439-48.

2. Behlau M. Voz: o livro do especialista. Volume I. 2 ed. Rio de Janeiro: Revinter, 2008;

3. Kunduck M, Mc Whorter AJ. True vocal fold nodules: The role of differential diagnosis. Curr Opin Otolaryngol Head Neck Surg. 2009; 17: 449-52.

4. Marcotullio D, Magliulo G, Pietrunti S, Suriano M. Exudative laryngeal diseases of Reinke's space: a clinicohistopathological framing. J Otolaryngol. 2002; 31:376-80.

5. Johns MM. Update on the etiology, diagnosis, and treatment of vocal fold nodules, polyps, and cysts. Curr Opin Otolaryngol Head Neck Surg. 2003; 11(6): 456-61.

6. Thiebeault SL. Advances in our understanding of the Reinke space: speech therapy and rehabilitation. Curr Opin Otolaryngol Head Neck Surg. 2005; 13(3): 148-51.

7. Pinho SMR. Fundamentos em fonoaudiologia. 2 ed. Rio de Janeiro: Guanabara Koogan, 2003.

8. Melo ECM, Tsuji DH. Histologia e Ultra Estrutura da Prega Vocal Humana. In: Pinho SMR, Tsuji DH, Bohadana SC. Fundamentos em Laringe e Voz. Rio de Janeiro: Revinter, 2006. p. 21-32.

9. Barbosa LHF, Ramos HVL, Neves LR, Biase NG, Oshima C, Pedroso JES, Pontes PAL. Detecção de receptor de ácido hialurônico em prega vocal humana por método imunohistoquímico. Rev Bras Otorrinolaringol. 2008; 74(2):201-6.

10. Dikkers FG, Nikkels PGJ. Lamina propria of the mucosa of benign lesions of the vocal folds. Laryngoscope. 1999; 109(10): 1684-9.

11. Melo ECM, Lemos M, Filho JAX, Sennes LU, Saldiva PHN, Tsuji DH. Distribution of collagen in the lamina propria of the human vocal fold. Laryngoscope. 2003; 113(12): 2187-91.

12. Gray S, Thibeault S, Tresco P. Witnessing a revolution in voice research: Genomics,tissue engineering, biochips and what's next! Logoped Phoniatr Vocol 2003; 28(1): 7-13.

13. Ramos HVL, Simões MJ, Pontes PAL, Neves LR, Barbosa LHF, Biase NG, Oshima CTS. Imunohistoquímica como método de estudo das fibras elásticas em prega vocal humana. Rev Bras Otorrinolaringol. 2005; 71(4): 486-91.

14. Hirschi SD, Gray SD, Thiebeault SL. Fibronectin: An Interesting Vocal Fold Protein. J Voice. 2002; 16 (3): 310-6.

15. Karkos PD, MacCormick M. The etiology of vocal fold nodules in adults. Curr Opin Otolaryngol Head Neck Surg. 2009; 17: 420-3.

16. Butler JE, Hammond TH, Gray SD. Genderrelated differences of hyaluran acid distribution in the human vocal fold. Laryngoscope.2001; 111(5):907-11.

17. Ward PD, Thiebeault SL, Gray SD. Hyaluronic acid: Its role in voice. J Voice. 2002; 16(3): 303-9. 
18. Thibeault SL, Gray SD, Li W, Ford CN, Smith ME, Davis RK. Genotypic and phenotypic expression of vocal fold polyps and Reinke's edema: A preliminary study. Ann Otol Rhinol Laryngol. 2002; 111:302-9.

19. Perazzo PSL, Duprat AC, Lancelotti C, Donati F. Estudo preliminar do comportamento histológico da prega vocal do coelho após injeção de ácido hialurônico. Rev. Bras. Otorrinolaringol. [online]. 2007, 73(2): 171-8 .

20. Chan RW, Gray SD, TITZE IR. The importance of hyaluronic acid in vocal fold biomechanics. Otolaryngol Head Neck Surg. 2001; 124(6): 607-14. 21. Koishi HU, Tsuji DH, Imamura R, Sennes LU. Variação da intensidade vocal: estudo da vibração das pregas vocais em seres humanos com videoquimografia. Rev Bras Otorrinolaringol.2003; 69(4): 464-70.

22. Nemr K, Amar A, Abrahão M, Leite GCA, Kohler J, Santos AO, Correa LAC. Análise comparativa entre avaliação fonoaudiológica perceptivo-auditiva, análise acústica e laringoscopias indiretas para avaliação vocal em população com queixa vocal. Revista Rev Bras Otorrinolaringol. 2005; 71:113-7.

23. Araujo AS, Grellet M, Pereira JC, Rosa MO. Normatização de medidas acústicas da voz normal. Rev Bras Otorrinolaringol. 2002; 68: 540-4.

24. Tuma J, Brasil OOC, Pontes PAL, Yasaki RK. Vestibular folds configuration in vocal nodule. Rev Bras Otorrinolaringol. 2005; 71(5): 576-81.

25. Gonzáles J, Cervera T, Miralles JL. Análisis acústico de la voz: fiabilidad de um conjunto de parámetros multidemensionales. Acta Otorrinolaringol Esp. 2002; 52: 256-68.

26. Fellipe ACN, Grillo MHMM, Grechi TH. Normatização de medidas acústicas para vozes normais. Rev Bras Otorrinolaringol. 2006; 72(5): 659-64.

27. Teles VC, Rosinha ACU. Análise Acústica dos Formantes e das Medidas de Perturbação do Sinal Sonoro em Mulheres Sem Queixas Vocais, Não Fumantes e Não Etilista. Arq Int Otorrinolaringol. 2008; 12(4): 523-30.

28. Hantzakos A, Remacle M, Dikkers FG, Delos JC, Delos M, Friederich G, Giovani A, Raumussen N. Exudative lesions of Reinke's space: a terminology proposal. Eur Arch Otolaryngol. 2009; 266: 869-78. 29. Melo ECM, Brito LL, Brasil OCO, Behlau M, Melo DM. Incidência de lesõeslaríngeas não neoplásicas empacientes com queixas vocais Rev Bras Otorrinolaringol.2001; 67(6):788-94.

30. Braga JN, Oliveira DSF, Atherino CT, Schott TCA, Silva JC. Nódulos vocais: Análise anátomofuncional. Rev CEFAC. 2006; 8(2): 223-9.

31. Dejonckere Kob M. Pathogenesis of vocal fold nodules: New Insights from modeling approach. Folia Phoniatr Logop. 2009; 61: 171-9.
32. Freitas MR, Weckx LL, Pontes PAL. Disfonia na Infância. Rev Bras Otorrinolaringol. 2000a; 66(3): 257-65.

33. Martins RHG, Fabro AT, Domingues MAC, Chi AP, Gregório EA. Is Reinke's Edema a Precancerous Lesion? Histological and Electron Microscopic Aspects. J Voice. 2009; 23(6): 721-5.

34. Wallis L, Jackson-Menaldi C, Holland W, Giraldo A. Vocal fold nodule vs. vocal fold polyp: Answer from surgical pathologist and voice pathologist point of view. J Voice. 2004; 18(1): 125-9.

35. Czerwonka L, Jiang J, Tao C. Vocal nodules and edema may be due to vibrationinduced rises in capillary pressure. Laryngoscope. 2008; 118:748-52.

36. Leonard R. Voice therapy and vocal nodules in adults. Curr Opin Otolaryngol Head Neck Surg. 2009; 17: 453-7.

37. Martins RHG, Domingues MA, Fabro AT, Dias NH, Santana MF. Edema de Reinke: estudo da imunoexpressão da fibronectina, da laminina e do colágeno IV em 60 casos por meio de técnicas imunoistoquímicas.Braz $\mathrm{J}$ Otorhinolaryngol.2009;75(6):821-5.

38. Allen JC, Belasfsky PC. Botulinum toxin in the treatment of vocal fold nodules. Curr Opin Otolaryngol Head Neck Surg. 2009; 17(6): 427-30.

39. Tauber S, Gross M, Issing WJ. Association of laryngopharyngealsymptoms with gastroesophageal reflux disease. Laryngoscope. 2002; 112:879-86.

40. Ratajczak J, Grzywacz K, Wojdas A, Raiejko $P$, Jurkiewicz $D$. Role of psychological factors in pathogenesis of disturbances of voice caused with vocal nodules. Otolaryngol Pol 2008; 62:758-63.

41. Martins RHG, Trindade SHK. A criança disfônica: Diagnóstico, tratamento e evolução clínica. Rev Bras Otorrinolaringol. 2003; 69(6): 801-6.

42. Bodt MS, Ketelslagers K,Peeters T, Wuyts FL, Mertens F, Pattyn J, Heylen L, Peeters A, Boudewyns A, Heyning PV. Evolution of Vocal Fold Nodules from Childhood to Adolescence. J Voice. 2007; 21(2): 151-6.

43. Freitas MR, Pela S, Gonçalves MLR, Fujita RR, Pontes PAL, Weckx LL. Disfonia crônica na infância e adolescência: estudo retrospectivo. Rev Bras Otorrinolaringol. 2000b; 66(5): 480-4.

44. Gama ACC, Behlau MS. Estudo da constância de medidas acústicas de vogais prolongadas e consecutivas em mulheres sem queixa de voz e em mulheres com disfonia. Rev Soc Bras Fonoaudiol. 2009;14(1):8-14.

45. Cecatto SB, Costa KS, Garcia RID, Haddad L, Júnior FVA, Rapoport PB. Vocal cords polyps: clinical and surgical aspects. Rev Bras Otorrinolaringol. 2002; 68(4): 534-8. 
46. Sakae FA, Sasaki F, Sennes LU, Tsuji DH, lamura R. Pólipos de pregas vocais e alterações estruturais mínimas: lesões associadas? Rev Bras Otorrinolaringol. 2004; 70(6): 743-8.

47. Yun YS, Kim MB, Son YI. The effect of vocal hygiene education for patients with vocal polyp. Otolaryngol. Head. Neck. Surg. 2007; 137(4):569-75.

48. Martins RHG, Defaveri J, Domingues MA, Silva RA. Vocal Polyps: Clinical, Morphological, and Immunohistochemical Aspects. J Voice. in press.

49. Wu P, Liu T, Zheng M, Chen J. Expression of vascular permeability factor in human vocal cord polyps. Lin Chuang Er Bi Yan Hou Ke Za Zhi. 2006; 20: 839-41.

50. Stajner-Katasic S, Horga D, Zrinski KV. A longitudinal study of voice before and after phonosurgery for removal of a polyp. Clin. Linguist. Phon. 2008; 22(10- 11): 857-63.

51. Ecley CA, Corvo MA, Yushimi R, Swensson J, Duprat AC. Unsuspected Intraoperative Finding of Structural Abnormalities Associated With Vocal Fold Polyps. Journal of Voice, in press.

52. Klein AM, Lehmann M, Hapner ER, Johns MM. Spontaneous Resolution of Hemorrhagic Polyps of the True Vocal Fold. J Voice. 2009; 23(1): 132-5.
53. Lazic MP, Babac SZ, Vukovic M, Kosanovic R, Ivankovic Z. Acoustic Voice Analysis of Patients with Vocal Fold Polyp. J Voice. in press.

54. Wang TG, Shau YW, HsiaoTY. Effects of Surgery on the Phonation Threshold Pressure in Patients With Vocal Fold Polyps. J Formos Med Assoc. 2010; 109(1): 62-8.

55. Cohen SM, Garrett CG. Utility of voice therapy in the management of vocal fold polyps and cysts. Otolaryngol Head Neck Surg. 2007;136: 742-6.

56. Jovanovick MB, Mulutinovic Z, Perovic J, Grubor A, Milenkovic S, Malobabic S. Contact telescopy reveals blood vessel alterations of vocal fold mucosa in Reinke's edema. J Voice. 2007; 21(3): 355-60.

57. Pastuszek $P$, Krecicki $T$, Zalesska-Krecicka M, Jelen M, Rak J, Krajewska B. Histological and electron microscopic investigation of Reinke's edema. Pol J Pathol. 2003;54:61-4.

58. Le Huche F, Allali A. A voz. Vol 2. Patologia vocal de origem funcional. 2 ed. São Paulo: Artmed, 2001. p. 15-27.
http://dx.doi.org/10.1590/S1516-18462011005000018

RECEBIDO EM: 03/09/2010

ACEITO EM: 08/11/2010

Endereço para correspondência:

Ana Rita Brancalioni

Rua: Guerino Catapan, 342

Ibiraiaras - RS

CEP: 95305-000

E-mail: fonoaninha@yahoo.com.br 